\title{
Protection of Traditional Knowledge: Finding an Appropriate Legal Framework for Bangladesh
}

\author{
Dr. Mohammad Towhidul Islam* and Moniruz Zaman**
}

\section{Introduction}

A legal framework for intellectual property (IP) tends to protect and enforce the rights of owners and creators for their inventions and creations in the form of patent, copyright, trademark and others. ${ }^{1}$ Such rights entitle the right holders with an exclusive legal right to prevent others from unauthorized uses of protected contents. ${ }^{2}$ Multiple theories, i.e., justificatory theory and monopolization theory are taken to support the protection of intellectual property - providing the owner limited monopolies over the use of creative contents. ${ }^{3}$ The justificatory theory which includes the labour theory, also known as the natural rights theory, justifies an individual's right to the product of his labour. ${ }^{4}$ Again, the theory of monopolization justifies a monopoly over how other people make use of owners' copies of an idea. ${ }^{5}$ For instance, the copyright holder or patent owner can control who can copy or reproduce the works or products, and can keep those off the market. Intellectual property rights (IPRs), ensuring ownership and monopoly over new creations, may arise from modifications of existing knowledge including traditional cultural expressions (TCEs) e.g. culture, stories, legends, folklore, rituals, songs, and laws, ${ }^{6}$ and traditional knowledge (TK) e.g. tools and techniques for hunting or agriculture), midwifery, ethnobotany and ecological knowledge, traditional medicine, celestial navigation, craft skills, ethnoastronomy, climate, and so on. ${ }^{7}$ However, who creates TCEs and TK and owns rights therein is a matter of controversy as the origin of such knowledge cannot be credited to any specific person. Hence, the protection of traditional

* Professor, Department of Law, University of Dhaka.

** Lecturer, Department of Law, Bangladesh University of Professionals.

1 Deborah E Bouchoux, Intellectual Property: The law of Trademarks, Copyrights, Patents, and Trade Secrets (4th edn, Cengage Learning 2012) 3.

David I Bainbridge, Intellectual Property (7th edn, Pearson Education Limited 2009) 11.

3 Mohammad Towhildul Islam, 'Implications of the TRIPS Agreement in Bangladesh: Prospects and Concerns' (2009) 6 Macquarie Journal of Business Law 4.

4 Millar v. Taylor (1769) 4 Burr. 2303, 98 Eng. Rep. 201 (Lord Mansfield CJ opined that, "It is just that an author should reap the pecuniary profits of his own ingenuity and labour").

5 Michele Boldrin and David K Levine, 'The Economics of Ideas and Intellectual Property' (2005) 102(4) Proceedings of the National Academy of Sciences of the United States of America 1252; Michael J Trebilcock and Robert Howse, The Regulation of International Trade (3rd edn, Routledge 2005) 398-99.

6 Bernard O'Connor, 'Protecting Traditional Knowledge: An Overview of a Developing Area of Intellectual Property Law' (2003) 6 Journal of World Intellectual Property 677, 678. ibid. 
knowledge seems to be one of the most complicated and contentious issues. The core of the controversy lies in the fact that TK which is usually considered as knowledge in the public domain, can be exploited without any cost, and even no respect or concern is shown to the relevant indigenous communities and local people who preserve and protect the knowledge.

To enquire how TK can be adequately protected in the absence of tailored legal instruments, it is required first to explain what 'traditional knowledge' actually is. In a narrower sense, TK commonly refers to knowledge, know-how, and practices maintained and developed by indigenous populations and local communities over generations of living. It evolves over centuries or even millennia by contributions of members of a particular society pursuant to the necessities of their local surroundings. ${ }^{8}$ In a broader sense, TK includes songs, stories, dance, handicraft, local language, proverbs, folklore, beliefs, cultural values, rituals, genetic resources, construction technologies, medicinal and agricultural practices, including plant and animal breeding available in the public domain. Within the context of TK, the meaning of 'traditional' implies that such knowledge is transmitted orally over generations and that it has been evolved in the course of long experience pursuant to a transmuting environment. ${ }^{9}$

In the $21^{\text {st }}$ century, holders of TK are found to face many challenges, and one of the growing concerns is 'bio-piracy' i.e. commercial misappropriation of traditional knowledge by an unauthorized third party without acknowledging the source or providing any form of compensation. Well-known examples include a patent on the use of neem, the patent on turmeric for healing wounds ${ }^{10}$, the patent on an Amazonian healing drink made form a plant ayahuasca ${ }^{11}$, the patent on an African sweetener serendipity berry (which produces Monellin) ${ }^{12}$, the patent on an African appetite suppressant plant Hoodia ${ }^{13}$, the patent on drought-resistant plant quinoa, and others. $^{14}$ It seems that western corporations, giant business houses, and research

8 Shahid Ali Khan and Raghunath Anant Mashelkar, Intellectual Property and Competitive Strategies in the 21st century (Kluwer Law International BV 2006) 77.

9 Afifah Kusumadara, 'Protection and Sustainability of Indonesian Traditional Knowledge and Folklore: Legal and Non-Legal Measures' (2011) 8 US-China Law Review 542, 548.

10 Philippe Cullet and others, 'Intellectual Property Rights, Plant Genetic Resources and Traditional Knowledge' in Susette Biber-Klemm and Thomas Cottier (eds), Rights to Plant Genetic Resources and Traditional Knowledge: Basic Issues and Perspectives (CABI 2006) 112, 135.

11 O'Connor (n 6) 682-83 (Ayahuasca patent was claimed by an American citizen Lorren Miller, and he obtained U.S. Plant Patent No. 5751).

12 Monnelin was also patented by University of Pennsylvania (US) and Kirin Brewery Ltd. (Japan); see, Rachel Wynberg, 'Privatising the Means for Survival: The Commercialisation of Africa's Biodiversity' (GRAIN, 20 May 2000) <https://www.grain.org/article/33-privatising-the-means-forsurvival-the-commercialisation-of-africa-s-biodiversity/print > accessed 23 February 2020.

13 Graham Dutfield, Intellectual Property, Biogenetic Resources and Traditional Knowledge (Earthscan 2004) 53.

14 ibid. 
companies have started to exploit the traditional knowledge without any acknowledgement and fair compensation for the indigenous communities who preserve and develop such knowledge over generations. Therefore, in today's IPRs regime, TK is at the risk of becoming extinct because the IPRs regime appears to be insufficient to prevent bio-piracy or to protect TK.

The United Nations Convention on Biological Diversity, $1992^{15}$ is the only treaty that recognizes the significance of traditional knowledge for enhancing the conservation and use of natural resources. Article 8(j) of the Convention establishes principles of 'respect, require and maintain', along with the ethical issues like equitable sharing of benefits with the creators and holders of TK. ${ }^{16}$ However, it 'does not recognize, and even less create, a property right in favour of indigenous peoples over their traditional knowledge. ${ }^{, 17}$ Further, the World Intellectual Property Organization (WIPO)'s Intergovernmental Committee (IGC) on 'Intellectual Property and Genetic Resources, Traditional Knowledge, and Folklore' is currently working on the development of an international set of instruments to protect genetic resources and associated traditional knowledge. ${ }^{18}$ For the protection of TK, the IGC is undertaking formal negotiations with WIPO members to develop a uniform legal instrument. However, the Committee is facing challenges to formulate an effective instrument because of the non-participation of the local people and indigenous communities in these negotiations. ${ }^{19}$

Now, looking into Bangladesh, it can be mentioned that the country has very rich bio-diverse resources, adapted from its local environment; there are at least 45 different ethnic and indigenous communities living here, who possess their own traditions, cultures, way of life, and customs. ${ }^{20}$ On multiple occasions, indigenous medicines like the medicinal plants used by the Kabirajes and folklores like 'Lalon

15 The Convention on Biological Diversity at the United Nations adopted on 22 May 1992 and entered into force 29 December 1993 [hereinafter CBD].

16 ibid, art 8(j). It requires Contracting States to "respect, preserve and maintain knowledge, innovations and practices of indigenous and local communities embodying traditional lifestyles relevant for the conservation and sustainable use of biological diversity and promote their wider application with the approval and involvement of the holders of such knowledge, innovations and practices and encourage the equitable sharing of the benefits arising from the utilization of such knowledge, innovations and practices".

17 Brendan Tobin and Krystyna Swiderska, Speaking in Tongues: Indigenous Participation in the Development of a Sui Generis Regime to Protect Traditional Knowledge in Peru (IIED 2001) 11.

18 Veronica Gordon, 'Appropriation without Representation? The Limited Role of Indigenous Groups in WIPO's Intergovernmental Committee on Intellectual Property and Genetic Resources, Traditional Knowledge, and Folklore' (2014) 16(3) Vanderbilt Journal of Entertainment and Technology Law 629.

19 ibid.

20 International Labour Organization, 'Brochure: Building Capacities on Indigenous and Tribal Peoples' Issues in Bangladesh: Rights and Good Practices’ (ILO, April 2017) 3. 
song' have been misappropriated or misused. ${ }^{21}$ This misappropriation takes place since the TK is largely unprotected due to the country's inadequate legal framework. Though Bangladesh has already signed several international conventions relating to protection of biodiversity related knowledge, still there exists a regulatory vacuum for which the Bangladeshi TK is vulnerable to misappropriation. The National Innovation and Intellectual Property Policy $2018^{22}$ (National IP Policy) in its Goal no. 6 mentions that a new law will be enacted to protect TK, existing IP laws will be reviewed, and the database of TK will be set up. Though the national IP Policy gives a time frame for the goal $^{23}$, it does not specify the detailed procedure for implementing it. In this article, therefore, the primary focus will be on the modalities and way-outs to protect traditional knowledge both in IP and non-IP framework.

\section{Traditional Knowledge of Bangladesh}

Bangladesh, a prosperous and bio-diverse country, has its very own traditional farming systems like floodplain production systems, fishing, and local environmental management practices. Its floodplain production system is considered as unique examples of agroecological systems at the land/water interface.$^{24}$ It is also endowed with a vast knowledge of cultural traditions like handicrafts, songs, dances, ceremonies and tales, and most of them are undocumented. Therefore, these traditional knowledge and practices are weakening, and in many cases, vanishing altogether. This is because of the copying, selling, or using these traditional knowledge by unauthorized third parties. ${ }^{25}$ For instance, a local laboratory developed 32 herbal formulations on Neem and continued its works under. However, later on, its collaboration with a local pharmaceutical company in 2013 weighed down its research works on herbal formulations using the traditional techniques. ${ }^{26}$

Despite the weakening trend, the following traditional knowledge have been commonly found in Bangladesh.

(a) Nakshi Kantha (embroidered quilt) - Nakshi Kantha requires an overarching craft skill as the embroidered surface of it encompasses a variety of folk

21 Md. Razidur Rahaman, 'Protection of Traditional Knowledge and Traditional Cultural Expressions in Bangladesh' (2015) 20 Journal of Intellectual Property Rights 164.

22 National Innovation and Intellectual Property Policy 2018 (Bangladesh) [hereinafter National IP Policy 2018] <https://dpdt.portal. gov.bd/site/page/e99a643b-6362-4717-b707-237baa4724af/> accessed 7 September 2020.

23 ibid, appendix 1.

24 Mursaleena Islam and John B Braden, 'Bio-economic Development of Floodplains: Farming versus Fishing in Bangladesh' (2006) 11(1) Environment and Development Economics 95.

25 Rahaman (n 21) 164.

26 'ACI's Deception Destroyed a Promising Domestic Industry' [in Bengali] The Daily Sangram (Dhaka, 29 October 2015) <https://rb.gy/onj2e3> accessed 6 September 2020. 
motifs derived from the surroundings of the artisan. ${ }^{27}$ It tells stories of the artisans' sentiments and beliefs by drawings and stitching various objects like flowers, leaves, plants, and animals. It displays the numerous running stitches which are ingeniously employed to form motifs and border patterns with the folk art of Bangladesh and West Bengal, India. The form of quilting that prevails in Bangladesh is unique in the sense that it reflects and represents cultural beliefs and identity. ${ }^{28}$

(b) Jamdani (a fine cloth of "muslin" group) - the Bangladeshi weave Jamdani has multicoloured linear or geometric design patterns along with floral motifs all over the body and woven painstakingly by hand on the old fashioned jala loom (a weaving device) ${ }^{29}$ The knowledge of weaving processes and patterns are orally passed from masters to apprentices through poetic recitation known as sloka or buli. ${ }^{30}$ It means that the knowledge is undocumented, and it is feared that this knowledge may face the risk of extinction in this modern era of globalization.

(c) Khadi (Eco-friendly textile) - Khaddar or Khadi, Comilla's traditional handloom cloth, is a kind of hand-woven or handspun textile primarily made out of cotton. In the $12^{\text {th }}$ century, Marco Polo had compared the khadi of Bengal with the top-notch version of the spider's web ${ }^{31}$. Even in 1921, Mahatma Gandhi came to Bangladesh to promote the khadi clothes of Comilla $^{32}$. The cloth is primarily made out of hemp and may also include wool or silk, which are all spun into yarn on a charka (a spinning wheel). ${ }^{33}$ The knowledge of the spinning and patterns of weaving khadi is known only to a handful of local weavers.

(d) Unani and Ayurvedic medicines - in traditional and alternative medicinal practices like Unani and Ayurvedic systems, about 500 medicinal plants have

27 Martha Alter Chen, 'Kantha and Jamdani: Revival in Bangladesh' (1984) 11(4) India International Centre Quarterly 45, 47.

28 Afroza Zaman Anni, 'Nakshi Kantha: Emotions Wrapped Up in Quilts' The Daily Sun (Dhaka, 23 August 2019) <https://www.daily-sun.com/printversion/details/417358/Nakshi-Kantha:-EmotionsWrapped-Up-In-Quilts> accessed 23 June 2020.

29 Mohammad Ataul Karim and Mohammad Ershadul Karim, 'Protection of 'Handicraft' as Geographical Indications under Municipal Law, TRIPS and BTAs vis-à-vis CETA: 'Bangladeshi Jamdani' as Case Study' (2017) 7(1) Queen Mary Journal of Intellectual Property 49, 51.

30 Sayyada R. Ghuznavi, 'Jamdani: The Legend and the Legacy' in National Crafts Council of Bangladesh (ed), Textile Tradition of Bangladesh (NCCB 2006) 48.

31 Mohammad Towhidul Islam and Md. Ahsan Habib, 'Introducing Geographical Indications in Bangladesh' (2013) 24 (1) Dhaka University Law Journal 51, 66.

32 Maheen Khan and Selim Ahmed, 'The Story of KHADI' The Daily Star (Dhaka, 13 December 2011) <https://archive.thedailystar.net/lifestyle/2011/12/02/centre.htm> accessed 12 March 2020.

33 Kriti Bhalla, Tarun Kumar and Jananee Rangaswamy, 'An Integrated Rural Development Model Based on Comprehensive Life-Cycle Assessment (LCA) of Khadi-Handloom Industry in Rural India' (2018) 69 Procedia CIRP 493. 
been used, and the majority of the rural communities are dependent on traditional medications for illnesses such as fever, cold, cough, dysentery, and headache. For instance, durba grass (Cynodon Dactylon) is widely used for congealing blood. Other widely used medicinal plants are Ashwagandha (Withaniasomnifera), Ashok (Saracaindica), Amloki (Embelicaofficnalis), Arjun (Termanaliaarjuna), Bael (Aeglemermelos), Anantamul (Hemidesmusindicus), Gulancha (Tinosporacordifolia), Miers, Shatomuli (Asparagus racemosus), Gritokumari (Aloe indica), Apang (Achyranthes-paniculata), Crown flower (Calotropisgigantia), Kalomegh (Androghaphis-pariculata), Ulotkombol (Abromaaugusta) etc. ${ }^{34}$

(e) Culinary Goods - culinary products, having traditional varieties, may include aromatic rice, desi ghee, and turmeric. In Bangladesh, varieties of aromatic rice like Kataribhog, Kaligira are widely used to produce delightful traditional foods, e.g., Biriyani, Pitha, Payesh, and Polau. ${ }^{35}$

(f) Food stuffs - the country is very rich in varieties of foods bearing traditions of each locality. Biriyani and Bakorkhani of Old Dhaka, Manda of Muktagachha, Mymensingh, Chomchom of Porabari, Tangail, Doi (curd) of Bogra, Roshmalai of Comilla, Kachagolla of Natore, Khejur Gur (molasses) of Manikganj and Jessore could be named as some of such items. ${ }^{36}$

(g) Dry fish - people living in the coastal region use traditional sun-drying practices and smoking of fish, shrimp and other fishery goods which are sold domestically and internationally. ${ }^{37} \mathrm{~A}$ Food and Agriculture Organization (FAO) data shows that fishing industries are continuously increasing in the world trade with the highest contribution from the developing countries with almost 56 per cent of the traded fishery products and Bangladesh is one of the countries. ${ }^{38}$

Islam and Habib (n 31) 51, 65.

EAM Asaduzzaman and Andrew Eagle, 'Aromatic Rice, Sweet Scent of Success' The Daily Star (Dhaka, 05 April 2018) <https://www.thedailystar.net/country/aromatic-rice-sweet-scent-success$1558123>$ accessed 26 June 2020.

Sun Online Desk, 'Six Sweetmeats which Branding Bangladesh' The Daily Sun (Dhaka, 19 May 2016) <https://www.daily-sun.com/post/137548/Six-sweetmeats-which-branding-Bangladesh> accessed 29 June 2020.

Parimal Chadra Paul and others, 'A Review on Dried Fish Processing and Marketing in the Coastal Region of Bangladesh' (2018) 5(3) Research in Agriculture Livestock and Fisheries 381; see also, Mohammad Towhidul Islam, 'How Bangladeshi Women Can Power Change through Innovation' The Daily Star (Dhaka, 26 April 2018) <https://www.thedailystar.net/opinion/perspective/howbangladeshi-women-can-power-change

throughinnovation 1567639\#: :text=Bangladeshi\%20women\%20can\%20also\%20claim,under\%20the $\% 20$ traditional\%20knowledge\%20regime> accessed 13 March 2020.

Food and Agriculture Organization of the United Nations (FAO), Trade in Fish and Fishery Products (FAO Support to the WTO Negotiations at the 11th Ministerial Conference in Buenos Aires, no. 18, 2017). 
(h) Household and decorative - household products of canes or sheetal pati (cool mat made of a kind of plant) of Barisal, Comilla, Tangail and Sylhet remind us the tradition and expertise of the local makers. ${ }^{39}$ Decoratives made of aluminium in Bikrampur or the ones made of brass in Jamalpur also have long traditions. Pottery items that had their concentrations in areas surrounding Dhaka and elsewhere in the country are also noteworthy. ${ }^{40}$

(i) Traditional Cultural Expressions - traditional cultural expressions include traditional songs i.e. Bhatiali, Baul, Marfati, Murshidi, and Bhawaiya, Jari, Sari, Lalon Geeti, etc., traditional dance i.e. Manipuri, Santhali etc., designs, ceremonies, tales and many other artistic or cultural expressions. ${ }^{41}$

(j) Genetic Resources - genetic resources (GRs), genetic material of plant or animal, are often connected to traditional knowledge and practices. GRs include plants (including trees), animals and crops, preparation or process i.e. techniques of using them for a final outcome, method of growing, harvesting, extracting, preparing, or applying them. ${ }^{42}$

Based on the above traditional knowledge, there are trade and businesses at home and abroad of local clothes, potteries and households, decorative pieces, handicrafts, indigenous foods, and herbal medicines. However, the trade is not satisfactory compared to the global context. For example, the size of the global exports of only handicrafts is almost US\$15 billion a year, whereas Bangladesh's share is a negligible \$8-9 million per annum. ${ }^{43}$ In addition, economic conditions of people working with traditional knowledge are worsening, and there are changes in their traditional profession. Traditional knowledge is also disappearing as it is misappropriated by unauthorized third parties, impacting people's livelihoods and health as the 'Kabiraz' (herbal practitioners) are not able to use the traditional medicinal plants which are now patented by others, ${ }^{44}$ replenishing the environment, and furthering climate change. ${ }^{45}$

39 Mamun Chowdhury, 'Shital Pati' The Daily Observer (Dhaka, 13 October 2017) <http://www.theindependentbd.com/magazine/details/118488/Shital-Pati> accessed 15 March 2020.

40 Kazi Nazrul Islam, 'Shariatpur Pottery Items are Exported Worldwide but the Potters are not Getting their Fair Share' Dhaka Tribune (Dhaka, 21 January 2019) <https://www.dhakatribune.com/ business/2019/01/21/shariatpur-pottery-items-are-exported-worldwide-but-the-potters-are-notgetting-their-fair-share> accessed 02 July 2020.

41 Ferdousi Rahman, 'Folk Songs of Bangladesh' The Daily Star (Dhaka, 27 March 2015) <https://www.thedailystar.net/arts-entertainment/music/folk-songs-bangladesh-73961> accessed 03 July 2020.

42 A K F H Bhuiyan, 'Farm Animal Genetic Resources in Bangladesh: Diversity, Conservation and Management' in Farm Animal Genetic Resources in SAARC Countries: Diversity, Conservation and Management (SAARC Agriculture Centre (SAC) 2014) 8.

43 Sharif Ahmed, 'Handicraft Exports See Steady Boom' The Independent (Dhaka, 01 January 2019) $<\mathrm{http} / / /$ theindependentbd.com/post/181332> accessed 25 March 2020.

44 Rahaman (n 21) 167.

45 ibid. The author showed that "farmers are exposed to modern farming techniques by abandoning their traditional farming knowledge and introducing modern varieties of corps caused a serious problem in agriculture". 


\section{Modalities and Approaches for Protecting Traditional Knowledge}

Given the amorphous nature of traditional knowledge, there is no uniform system of effective protection measures. Various strategies have been followed to protect TK, whether positive or defensive. ${ }^{46}$ While positive protection strategies rely on existing IP measures, defensive strategies prevent others from obtaining IP rights over preexisting TK. ${ }^{47}$ Generally, the defensive measure is the defensive use of the patent mechanism and the creation of traditional knowledge database. ${ }^{48}$ By contrast, offensive or positive protection is the existing IP laws such as copyrights and related rights, trademarks, plant varieties protection, industrial designs, geographical indications, and trade secrets (unfair competition) law. ${ }^{49}$ Conceptually, though both the strategies pose obstacles to the guardian of $\mathrm{TK}^{50}$, a meaningful TK protection scheme may contain elements of both of these categories.

\section{Conventional IP Protection Mechanism}

The conventional IPRs system, commonly referred to as industrialized tools, promotes individual and corporate ownership with an aim to encourage innovation. Given the collective nature of TK, the classic IP instruments are not adequate for protecting genetic resources and community-based knowledge of the local and indigenous communities. Classic IP tools, or maybe their revised versions in some cases, can be used to protect TK though each of the tools has various benefits and deficiencies such as disclosure requirements and a fixed duration of protection. However, conventional IP instruments that can be used by the indigenous and local people in Bangladesh to protect their IP in TK may include trademarks, trade secrets, copyrights, patents, and geographical indications.

\subsection{Patent}

A patent is the first option for the local community to protect inventions arising of TK. Generally, a patent is a bundle of exclusive rights granted to the inventors for their inventions (processes or products) for a limited period of time. In Bangladesh, section 2(8) of the Patents and Designs Act, 1911 defines 'invention' as 'any manner of new manufacture and includes an improvement and an alleged invention'. ${ }^{51} \mathrm{~A}$

46 Jonathan Curci, The Protection of Biodiversity and Traditional Knowledge in International Law of Intellectual Property (Cambridge University Press 2010) 20.

47 Pitipong Yodmongkon and Nopasit Chakpitak, 'Applying Intellectual Capital Process Model for Creating a Defensive Protection System to Local Traditional Knowledge: The Case of Mea-hiya Community' (2009) 7(4) Electronic Journal of Knowledge Management 518.

48 Margo A Bagley, 'The Fallacy of Defensive Protection for Traditional Knowledge' (2019) 58 Washburn Law Journal 323, 326.

49 Deepa Varadarajan, 'A Trade Secret Approach to Protecting Traditional Knowledge' (2011) 36(2) Yale Journal of International Law 371, 383.

50

51 Patents and Designs Act 1911 (Bangladesh), s 2(8). 
patent holder gets a certificate or document issued by the government department (for example in Bangladesh it is the Department of Patents, Designs and Trademarks) for his invention or innovation for a period of 16 years as per section 14 if the invention fulfils the criteria of new (novelty), inventive step (non-obviousness) and industrial application (usefulness in the industry).

Here, novelty means that the invention must be new, of which no prior art exists. Since TK is that knowledge, which is used and transmitted over generations, it cannot fulfil the requirement of a novelty for patent protection. Further, the notion of the prior art can be used as an effective strategy to provide defensive protection if TK is included efficiently in the prior art. A patent examiner while assessing the patentability of an invention can disprove the claimed invention to be patented if it is already in the prior art. To use this strategy, it is necessary for the indigenous community to maintain an open database for TK. Interestingly, the Draft Bangladesh Patent Act, $2019^{52}$ specifically provides for defensive protection in some of its sections in order to cater to the protection of traditional knowledge. For instance, section 4(1)(o) of the draft Act specifically mentions that inventions from traditional knowledge or combinations of any traditionally known ingredients are outside the scope of patent protection. Additionally, section 16 mentions that any interested person can apply to the court for revocation of any patent, and the patent for the claimed invention will be invalidated if it can be proved that the invention contains ingredients replicated from traditional knowledge.

Further, TK patents in Bangladesh can be effectively utilized to protect mechanical innovations of traditional healers or farmers concerning products on traditional medicines, or processes of making such products, which may include cooling, drying, mixing, washing and moulding compositions for a herbal brew. However, there are numerous reasons for which patent law might not represent a feasible arrangement to protect biodiversity and associated traditional knowledge. First, the patent application requires disclosing the knowledge to the public after a certain period. ${ }^{53}$ In Bangladesh, after eighteen months of a patent's approval, it is made available to the public. Second, the protection is limited in nature. For example, the patent is protected for 20 years under the TRIPS Agreement, $1994,{ }^{54}$ and in Bangladesh, it is protected for 16 years which may be extended up to another 10 years by presenting a petition to the government. ${ }^{55}$ Third, it involves some stringent criteria as stated above like the 'criteria of novelty and inventive steps'.

52 Draft Patent Act 2019 (Bangladesh) [On file with the author].

53 Marcia Ellen DeGeer, 'Biopiracy: The Appropriation of Indigenous Peoples' Cultural Knowledge' (2003) 9 New England Journal of International \& Comparative Law 179, 181.

54 Agreement on Trade-Related Aspects of Intellectual Property Rights, 15 April 1994 (33 ILM 1197), art 33 [hereinafter TRIPS].

55 Patents and Designs Act 1911 (Bangladesh), ss 14, 15. 


\subsection{Copyright}

A copyright is an exclusive right owed to the author of creative ideas which are expressed in a material form such as in a literary, musical, artistic, dramatic, or educational form. ${ }^{56}$ In Bangladesh, the copyright lasts for 60 years plus the life of the author. ${ }^{57}$ The Copyright Act, 2000 provides for the protection of original literary, artistic, musical and dramatic works. ${ }^{58}$ Hence, the copyright can protect the original artistic works of the TK holders such as literary works (i.e. myths, tales, poems), theatrical works, musical works, textile works (i.e. garments, fabrics, carpets) and three-dimensional works (i.e. sculptures, pottery and ceramics). ${ }^{59}$ It is to be remembered that for a work to be eligible for copyright, it does not compulsorily require to be registered but it must be expressed in a material form (commonly referred to as the 'fixation requirement'). ${ }^{60}$ As such, anyone reading or hearing the unwritten traditional literary and musical works can use those without infringing the copyright. ${ }^{61}$

However, the Copyright Act, 2000 grants exclusive rights only to 'creative individuals' and it does not acknowledge community ownership, and as such collective creativity of the local and indigenous communities does not fall within the ambit of copyright protection. ${ }^{62}$ Though the Act of 2000 does not recognize 'folk knowledge', the draft Copyright Act, 2019 defines' folk knowledge' as folk skills, information, and culture handed over from generation to generation through oral, written or other means. In addition, tangible and intangible folk elements and expressions will be treated as 'folk culture'. ${ }^{63}$ The culture of Bangladesh's ethnic minorities will also be part of these definitions. Significantly, the draft Act prohibits the use of folk knowledge or folk culture, and hence folkloric expressions are protected in perpetuity. By the help of this Act, indigenous artists of Bangladesh will be able to collect royalties from the users of their works. The example of this can be seen in an Australian case of Milpurrurru \& Ors v. Indofurn Pty Ltd \& Ors..$^{64}$, where Vietnam wove several carpets incorporating aboriginal designs of Australian artists. The court then held that the copyright of the aboriginal artists had been infringed and

56 L Ray Patterson, 'Copyright and the Exclusive Right of Authors' (1993) 1 Journal of Intellectual Property Law 1.

57 Copyright Act 2000 (Bangladesh), s 24.

58 ibid, s 15.

59 Simon Stokes, Art and Copyright (Bloomsbury Publishing 2012) 3.

60 Evan Brown, 'Fixed Perspectives: The Evolving Contours of the Fixation Requirement in Copyright Law' (2014) 10 Washington Journal of Law, Technology \& Arts 17, 18.

61 Josephine R Axt and others, Biotechnology, Indigenous Peoples, and Intellectual Property Rights (Congressional Research Service 1993).

62 Copyright Act 2000 (Bangladesh), s 14.

63 Draft Copyright Act 2019 (Bangladesh) [On file with the author].

64 (1995) 30 IPR 209. 
the artists were to be given royalties for those carpets. ${ }^{65}$ In this case, the court recognized the concepts of "cultural harm" and efficaciously utilized the realm of copyright to protect TK. ${ }^{66}$ Hence, the copyright can successfully protect TK by promoting traditional values and preventing misuse of indigenous works.

\subsection{Trademarks}

The trademark protects brand names, symbols or signs that assist consumers to avoid confusion between similar products of different traders. In Bangladesh, the Trademarks Act, 2009 defines trademarks as 'registered marks' and also includes 'service marks' concerning the trade of goods; $;{ }^{67}$ and an individual may register a trademark by writing an application to the Registrar in the prescribed manner. ${ }^{68}$ In all cases, a trademark should be distinctive and not deceptive. ${ }^{69}$ Unlike patents, the registration ${ }^{\mathrm{R}}$ protects a trademark for seven years and is subject to indefinite renewals for ten years on each occasion on payment of prescribed fees. ${ }^{70}$ An unregistered well-known trademark can also be protected by fulfilling the use requirements including a claim of trademark ${ }^{\mathrm{TM}}$ for products or service mark ${ }^{\mathrm{SM}}$ for services in a passing off action. ${ }^{71}$ Trademarks, therefore, may be used to protect symbols or signs of manufactured goods and services offered by local people or indigenous communities. The native and indigenous group can now easily gain economic benefits by selling the TK products using the registered or claimed signs or symbols, even if there are no patents on those TK products.

Additionally, certification marks, another form of trademark, can be used to protect the procedure or process of making TK products of an indigenous group. Collective marks can also be used to protect products of a registered group or local community. ${ }^{72}$ Countries like France, South Africa, Peru, and Chile are effectively using collective marks in the wine and spirit industries. In Bangladesh, collective marks also can be used to protect the community's $\mathrm{TK}^{73}$ Under collective marks, the community owns the mark and all of its members can use the mark like other trademarks. ${ }^{74}$ Thus, trademarks can be

65 Michael Blakeney, 'Milpurrurru and Ors vs. Indofurn Pty Ltd and Ors: Protecting Expressions of Aboriginal Folklore under Copyright Law' (1995) 2(1) Murdoch University Electronic Journal of Law <http://www5.austlii.edu.au/au/journals/MurUEJL/1995/4.html> accessed 03 April 2020.

O'Connor (n 6) 688.

Trademarks Act 2009 (Bangladesh), s 2(8).

ibid, s 15.

ibid, s 8 .

ibid, s 22.

Shujie Feng, 'How Are Unregistered Trademarks Protected in China?' (2013) 44(7) IICInternational Review of Intellectual Property and Competition Law 815, 823.

72 Teshager W Dagne, 'Law and Policy on Intellectual Property, Traditional Knowledge and Development: Legally Protecting Creativity and Collective Rights in Traditional Knowledge-Based Agricultural Products through Geographical Indications' (2010) 11(1) Estey Centre Journal of International Law \& Trade Policy 68, 82.

Trademarks Act 2009 (Bangladesh), s 2(25).

Paris Convention for the Protection of Industrial Property 1883 (828 UNTS 305), art 7bis. 
an effective tool both in cases of adequate protection and indefinite duration, unlike the limited protection of patent and copyright.

\subsection{Trade Secrets}

Trade secrets can protect traditional knowledge as long as the knowledge remains secret. ${ }^{75}$ In addition to the secrecy requirement, the knowledge must also possess commercial value and must not be in the public domain. ${ }^{76}$ Trade secret creators, thus, have sole control over the goods or products, and the best example of it is the formula of Coca Cola beverages. TK holders of secret and sacred TK, like healers (shamans) or other specialist TK holders who have gathered knowledge through ages, can prevent knowledge from disclosure to others under the system of trade secrets. Usually, trade secrets are enforceable in the courts of Bangladesh by following contract law principles. ${ }^{77}$ However, indigenous communities will no longer get the TK protection as a trade secret if the knowledge leaks into the public, and anyone can use that knowledge and reverse engineer it.

The native and indigenous community can collect royalties from a specific company by sharing the knowledge with a condition of confidentiality that the company will not publish the knowledge without permission of the TK holders. Generally, native tribes or traditional healers, who use plants for medicinal purpose, can make such arrangements with a particular outside organization. Such royalty payment arrangements remain intact even if the knowledge diffused into the public domain. As in the 'Listerine' formula case ${ }^{78}$, an American citizen J J Lawrence developed an antiseptic mouthwash and named it as 'listerine' which was listed as a trade secret. He made royalty agreements with a pharmaceutical corporation. Later, the formula published in a journal and made the knowledge available to the public. The US court held that because of the trade secret licensing, the company had to pay royalties according to the agreement even if the formula is diffused in the public domain. $^{79}$

\subsection{Geographical Indications (GIs)}

Geographical indications (GIs), another form of IP protection, provides protection to goods having specific geographical origin possessing geographical denomination, reputation or other characteristics even though the raw materials may

\footnotetext{
Varadarajan (n 49) 375.

Ibid, 408.

77 Mohammad Towhidul Islam, TRIPS Agreement of the WTO: Implications and Challenges for Bangladesh (Cambridge Scholars Publishing 2013) 125.

78 Warner-Lambert Pharmaceutical Company, Inc. v. John J. Reynolds, Inc., 178 F. Supp. 655; 1959 U.S. Dist. LEXIS 2567.

79 Stephen Hansen and Justin Van Fleet, Traditional Knowledge and Intellectual Property: A Handbook on Issues and Options for Traditional Knowledge Holders in Protecting Their Intellectual Property and Maintaining Biological Diversity (AAAS 2003) 29.
} 
be sourced from elsewhere. ${ }^{80}$ If a connection can be forged between products and geographical territory, a GI can be claimed to generate rewards for the members of an established community who maintains traditional methods in producing the products. GIs are especially designed to reward reputation and goodwill maintained from generations to generations. ${ }^{81}$ As such, GIs may be the most suitable mechanism to protect TK-based products like indigenous handicrafts and agro-food products ${ }^{82}$, especially from the perspective of a least developed country like Bangladesh. Considering the significance of cultural GI products, article 22 of the TRIPS Agreement makes it mandatory for its member countries to formulate legislation protecting GIs. ${ }^{83}$ In Bangladesh, the Geographical Indications (Registration and Protection) Act, $2013^{84}$ gives protection to both GI (goods originate from a geographical location having a reputation) and Appellation of Origin (goods originate from a geographical location having a reputation and the raw materials sourced therein as well) by providing provisions for registration of GIs. If the indication can be traced to its geographical origin, the unregistered GIs can also be protected. ${ }^{85}$ The Act gives wider protection in the sense that it protects homonymous GIs as well. ${ }^{86}$

Like trademarks, GIs give perpetual protection as long as the traditional quality and reputation are maintained. Though geographical indications prevent misappropriation of indications, they do not protect the underlying knowledge per se. ${ }^{87}$ It means that GIs are aimed at protecting the names of traditional products, not specific knowledge, or technology. Further, it is quite realistically impossible to protect all forms of TK only by using the single form of IP protection that is geographical indications; however, it is well recognized as a complementary tool to protect $\mathrm{TK}^{88}$

80 TRIPS, art 22.1

81 Kal Raustiala and Stephen R Munzer, 'The Global Struggle over Geographic Indications' (2007) 18(2) European Journal of International Law 337.

82 Teshager Worku Dange, 'Harnessing the Development of Potential Geographical Indications for Traditional Knowledge Based Agricultural Products' (2010) 5(6) Journal of Intellectual Property Law \& Practice 441.

83 See TRIPS, art 22(2)(a) (requiring that Members change their laws in order to give litigants the legal means to block "designation or presentation of a good that indicates or suggests that the good in question originates in a geographical area other than the true place of origin in a manner which misleads the public"); see also, Kevin M Murphy, "Conflict, Confusion, and Bias under TRIPS Articles 22-24' (2003) 19 American University International Law Review 1181, 1185.

84 Geographical Indications of Goods (Registration and Protection) Act 2013 [hereinafter GI Act 2013].

85 GI Act 2013 (Bangladesh), s 6(1).

86 ibid, s 7. It provides that a homonymous geographical indication of goods may be registered under this Act.

87 Annette Kur and Roland Knaak, 'Protection of Traditional Names and Designations' in Silke von Lewinski (ed), Indigenous Heritage and Intellectual Property (Kluwer Law International 2004) 227.

88 David R Downes, 'How Intellectual Property Could Be a Tool to Protect Traditional Knowledge' (2000) 25 Columbia Journal of Environmental Law 253. 


\section{Modalities and Possible Way-outs for Protecting Traditional Knowledge: Beyond IP Regime}

At present, apart from the use of conventional IP law mechanism - four distinct modalities have been suggested: first is the use of access and benefit sharing (ABS) scheme with prior informed consent (PIC), the second one is the TK digital library models, third is the creation of sui generis (of its own kind) laws, and the fourth one is the contractual agreements.

\subsection{Access and Benefit Sharing (ABS) Scheme mandating PIC}

The CBD, along with a supplementary, non-binding agreement - the Nagoya Protocol, 2010 ${ }^{89}$ established the Access and Benefit Sharing (ABS) scheme to regulate the conditions for the access and benefit-sharing (ABS) of genetic resources, and associated $\mathrm{TK}^{90}$ The CBD requires its parties to promote sharing of benefits from the utilization of TK with local peoples and indigenous communities, while article 5 of the Nagoya Protocol ${ }^{91}$ mandates to obtain the prior informed consent of the holders of TK and to share its benefits with them. Therefore, the ABS system aims to create a win-win situation - conserving biological resources and TK associated with those resources and generating prospects to obtain a fair and equitable share of benefits from each country's array of bio-diverse resources.

Access to genetic resources, benefit-sharing, and bioprospecting are the significant components of ABS regimes. ${ }^{92}$ These aspects of the ABS regime should be prioritized and included in the respective regional and national ABS legislation. ${ }^{93}$ Recently, Bangladesh has enacted the Bangladesh Biological Diversity Act, 2017 ${ }^{94}$, which introduces the ABS mechanism with an aim to confer fair and equitable

89 Nagoya Protocol on Access to Genetic Resources and the Fair and Equitable Sharing of Benefits Arising from their Utilization to the Convention on Biological Diversity (adopted on 29 October 2010 in Nagoya and entered into force on 12 October 2014) (The Nagoya Protocol); see also, Press release of CBD <https://www.cbd.int/kb/record/pressRelease/81865?RecordType=pressRelease> accessed 6 September 2020 (Bangladesh is the forty-second signatory to the Nagoya Protocol).

Chidi Oguamanam, 'Genetic Resources, Access and Benefits Sharing: Politics, Prospects and Opportunities for Canada after Nagoya' (2011) 22(2) Journal of Environmental Law and Practice 87, 92-94.

91 The Nagoya Protocol, art 5 (art 5(2) states that "each Party shall take legislative, administrative or policy measures, as appropriate, with the aim of ensuring that benefits arising from the utilization of genetic resources that are held by indigenous and local communities, in accordance with domestic legislation regarding the established rights of these indigenous and local communities over these genetic resources, are shared in a fair and equitable way with the communities concerned, based on mutually agreed terms.").

92 Krishna Prasad Oli and Tara Devi Dhakal, Access and Benefit Sharing from Genetic Resources and Associated Traditional Knowledge (International Centre for Integrated Mountain Development 2009) 19.

93 ibid.

94 Bangladesh Biodiversity Act 2017 <http://bdlaws.minlaw.gov.bd/bangla_pdf_part.php?id=1203> accessed 3 April 2020. 
benefit-sharing by preventing the misappropriation and unapproved use of genetic resources. The Act provides a framework about when the transfer of research results based on biodiversity or biological resources will not be prohibited ${ }^{95}$ and how a person can apply for a patent or any other form of IPRs for an invention relating to biological resources found in Bangladesh. The Act prohibits anyone explicitly from applying for any IP right for any invention premised on any study or data on a biological resource obtained from Bangladesh without the prior approval of the National Biodiversity Committee. ${ }^{96}$ However, the Committee may approve the application for such patents or other forms of IPRs relating to Bangladeshi biological resources by imposing specific royalties or benefit-sharing fees or both. ${ }^{97}$ It may also impose conditions or lay down a procedure to share the economic paybacks from the commercial use of such IP rights. ${ }^{98}$

In addition, section 23(1) of the Plant Variety Protection Act, $2019^{99}$ (the PVP Act) explains benefit-sharing as the action of giving a portion of the benefits to the breeder from a licensee or agent of plant varieties, and for which the farming community (the claimant) shall be entitled to demand such benefits under this Act. ${ }^{100}$ The Act in section 17 proposes that applicants will not be given the PVP protection in case of failure to produce sufficient evidence of farmer's knowledge in breeding the variety. ${ }^{101}$ The lifespan of plant varieties protection ranges from 14 to 16 years under section 22 of the Act. ${ }^{102}$ A statutory authority named 'Plant Variety Protection Authority' is designed under section 4 of the Act to ensure farmers' access right of benefit-sharing arising from the utilization of plant genetic resources. ${ }^{103}$

\subsection{TK digital library (TKDL) models}

The TKDL is a protective anti-appropriation device, also considered a non-legal mechanism, which makes a compilation of TK in a digitized format so that it can be accessed by the patent examiners in future patent claims. So, by placing the knowledge in the public domain, it is easier to prevent others from obtaining a patent as the requirement of novelty cannot be claimed in respect of the disclosed information. However, the major problem of the TKDL system is that the information is in a searchable database; individuals with such information may claim a patent on a

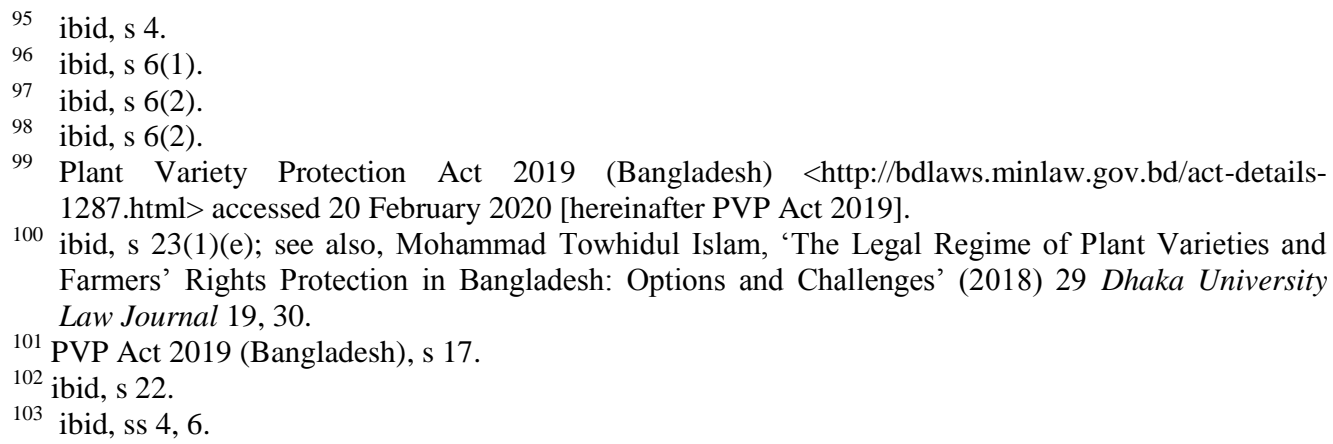

100 ibid, s 23(1)(e); see also, Mohammad Towhidul Islam, 'The Legal Regime of Plant Varieties and Farmers' Rights Protection in Bangladesh: Options and Challenges' (2018) 29 Dhaka University Law Journal 19, 30.

${ }^{101}$ PVP Act 2019 (Bangladesh), s 17.

102 ibid, s 22.

103 ibid, ss 4, 6. 
modified invention. ${ }^{104}$ For instance, a local community of Bangladesh provides a piece of information to the TKDL regarding a medicinal plant for its healing abilities. Not let us say an outsider with such available information produces an entirely new drug, and if it fulfils the required levels of novelty and inventiveness, then the drug is patentable. The TKDL model can thus be regarded as double-edged, which can actually worsen the problem of unauthorized use of traditional knowledge. ${ }^{105}$

Looking at our neighbouring country India, it is using the TKDL format as defensive protection to protect its traditional medicinal knowledge. With the TKDL, India is capable of winning almost 105 claims on international patents like the patent on the use of turmeric ${ }^{106}$ and another patent on the use of neem. ${ }^{107}$ In Korea, the "Korean Intellectual Property Office (KIPO)" introduces the "Korean Traditional Knowledge portal (KTKP)" for documenting ancient Korean medicine. ${ }^{108}$ Similarly, in China, there is a Chinese Traditional Medicine (CTM) patent database system. ${ }^{109}$ So, it seems that the documentation of traditional knowledge in digital form has gained prominence in various nations in their fight against the biopiracy cases.

\subsection{Sui Generis Modality}

Given the existing IPRs regime, even with some modifications, is not adequate to protect traditional knowledge effectively, many countries like India, Brazil, Portugal, Peru, and the Philippines have adopted sui generis measures of TK protection. ${ }^{110}$ The sui generis model is commonly referred to as the 'defensive community patent' model. ${ }^{111}$ In order to make an IP system sui generis, it involves alteration of some of its characteristics to take care of the unique nature and features of TK, which leads to the creation of a distinct system.

104 Ikechi Mgbeoji, 'Patents and Traditional Knowledge of the Uses of Plants: Is a Communal Patent Regime Part of the Solution to the Scourge of Bio Piracy?' (2001) 9 Indian Journal of Global Legal Studies 163, 172.

105 Chidi Oguamanam, 'Documentation and Digitization of Traditional Knowledge and Intangible Cultural Heritage: Challenges and Prospects' in Toshiyuki Kono (ed), Intangible Cultural Heritage and Intellectual Property: Communities, Cultural Diversity and Sustainable Development (Intersentia 2009) 357-383.

106 Case of Turmeric Patent (Curcuma longa) US Patent No. 54015041.

107 Case of Neem Patent (Azadiracha Indica) EPO Patent No. 436257; see also, Kasim Musa Waziri, 'Protection of Traditional Knowledge in Nigeria: Breaking the Barriers' (2014) 29 Journal of Law, Policy and Globalization 176, 182.

108 R Lakshmi Poorna, Mymoon Moghul and Arunachalam Hariharan, 'Preservation and Protection of Traditional Knowledge: Diverse Documentation Initiatives across the Globe' (2014) 107 Current Science 1240, 1242.

109 ibid.

${ }^{110}$ Carlos Maria Correa, 'Traditional Knowledge and Intellectual Property: Issues and Options Surrounding the Protection of Traditional Knowledge' (2001) The Quaker United Nations Office (QUNO) Discussion Paper November 2001, 17.

111 Mgbeoji (n 104) 163; see also, James D Nason, 'Traditional Property and Modern Laws: The Need for Native American Community Intellectual Property Rights Legislation’ (2001) 12 Stanford Law \& Policy Review 255. 
A sui generis model law at the domestic level aims at protecting TK associated with the utilization of genetic resources, establishing prerequisites on access to biodiversity-related TK, and calls for respect, preservation and maintenance of the Cosmo vision, customs and practices of the concerned local and indigenous communities. ${ }^{112}$ In order to avoid the conflict between a sui generis model law and the current national laws, a sui generis modality requires to amend relevant existing national legislation that governs intellectual property rights, protected areas, natural resources, land occupation and protection of the environment.

A number of sui generis legislative models exists around the world ${ }^{113}$ like the 'Model Provisions for National Laws on the Protection of Expressions of Folklore against Illicit Exploitation and Other Prejudicial Actions, ${ }^{114}$. The Model Provisions consist of 14 sections, and section 1 explains the principle of protection. Section 14 determines the 'conditions under which expressions of folklore originating from a community in a foreign country are protected'. Another legislative model is the 'Principles and Guidelines for the Protection of the Heritage of Indigenous People' 115 which is elaborated by the Sub-Commission on Prevention of Discrimination and Protection of Minorities. ${ }^{116}$ Principle 3 of the 'Principles and Guidelines for the Protection of the Heritage of Indigenous People' states that, 'Indigenous peoples should be recognized as the primary guardians and interpreters of their cultures, arts and sciences, whether created in the past, or developed by them in the future'. ${ }^{117}$ Other models include the 'Third World Network's Proposal for a Rights Regime for the Protection of Indigenous Rights and Biodiversity'118, the 'Intellectual Integrity Framework of the RAFI" ${ }^{119}$, the 'Model Biodiversity Related Community Intellectual Rights Act of the Research Foundation for Science, Technology and Ecology ${ }^{120}$, and

112 Kerry ten Kate and Sarah A Laird, The Commercial Use of Biodiversity-Access to Genetic Resources and Benefit Sharing (Earthscan 1999) 33.

113 Shamama Afreen and Biju Paul Abraham, 'Biopiracy and Protection of Traditional Knowledge: Intellectual Property Rights and Beyond' (2008) Indian Institute of Management Calcutta Working Paper Series 629/September 2008 <https://www.iimcal.ac.in/sites/all/files/pdfs/wps-629_1.pdf> accessed 12 September 2020.

114 'Model Provisions for National Laws on the Protection of Expressions of Folklore against Illicit Exploitation and other Prejudicial Actions, with a commentary' <https://unesdoc.unesco.org/ark:/ 48223/pf0000220163> accessed 13 September 2020.

115 Principles and Guidelines for the Protection of the Heritage of Indigenous People (Draft) (UN, 21 June 1995).

116 (E/CN.4/Sub.2/1995/26).

117 Principles and Guidelines for the Protection of the Heritage of Indigenous People (n 115).

118 Third World Network, 'A Conceptual Framework and Essential Elements of a Rights Regime for the Protection of Indigenous Rights and Biodiversity' (1996) cited in G S Nijar, 'In Defence of Local Community Knowledge and Biodiversity: A Conceptual Framework and the Essential Elements of a Rights Regime' (1996) Third World Network Briefing Paper 1996, 1.

119 Rural Advancement Foundation International (RAFI), Conserving Indigenous Knowledge: Integrating Two Systems of Innovation (UNDP 1994) 1-79.

${ }^{120}$ Model Biodiversity Related Community Intellectual Rights Act 1997 (Drafted by Research Foundation for Science, Technology and Ecology). 
the 'Draft Legislation on Community Rights and Access to Biological Resources developed by the OAU ${ }^{121}$. Most of these models are non-legal, and voluntary mechanisms and hence, cannot bind the countries to adhere to them.

A sui generis modality, thus, may contain some standard practices of IP protections along with the fusion of some other practices of protections for genetic resources. For instance, a country can offer protections for inventions with patent law, or it can protect plant varieties with Plant Varieties Certificate (PVC) ${ }^{122}$, and it can nullify inappropriate patents. These fusion protections are found in the law 27811 of Peru, which combines several protection mechanisms like licenses, registers, competition law, trade secret and defensive protection principles. ${ }^{123}$ A sui generis system of Costa Rica ${ }^{124}$ suggests that TK can be protected even if it is not documented correctly, however in that case, the knowledge of the intellectual property office of the government about TK is necessary in order to enforce the protection. This system establishes a working relationship between the intellectual property office and local communities. So, it seems that a new sui generis mechanism can only be effective if it is based on the customary laws of indigenous people. By enacting the Biodiversity Act, Bangladesh has initiated its steps forward to craft a distinct system of law for the protection of genetic resources and biodiversity related TK.

\subsection{Contractual Agreements}

Contractual agreements, ${ }^{125}$ containing especially the restrictions on the use of TK, are legally binding documents which regulate relationship between the society and the inventor. ${ }^{126}$ Hence, contract-based agreements can be utilized as an additional apparatus to protect TK; agreements are also regarded as voluntary mechanism between the parties. Most importantly, these agreements include the duration of the agreement, patent specification, IP ownership, confidentiality clause and benefit sharing mechanism. National courts of Australia, New Zealand and South Africa

121 'African Model Legislation for the Protection of the Rights of Local Communities, Farmers and Breeders, and for the Regulation of Access to Biological Resources' <https:/www.wipo.int/edocs/ lexdocs/laws/en/oau/oau001en.pdf> accessed 13 September 2020.

122 Scott D Locke, 'Intellectual Property for the Botanist and the Plant Breeder: An Overview of Protection Afforded by Plant Patents and Plant Variety Protection Certificates' (2006) 6 ChicagoKent Journal of Intellectual Property 198 (Plant Varieties Certificate is completely different than the plant patent).

123 Muller Manuel Ruiz, 'The Legal Protection of Widely Shared and Dispersed Traditional Knowledge' in Daniel F Robinson, Ahmed Abdel-Latif, and Pedro Roffe (eds), Protecting Traditional Knowledge (Routledge 2017) 122, 123.

124 Biodiversity Law 1998 (Costa Rica), art 82.

${ }^{125}$ For sample contractual agreements, see Michael A Gollin, 'Elements of Commercial Biodiversity Prospecting Agreements' in Sarah A Laird (ed), Biodiversity and Traditional Knowledge: Equitable Partnerships in Practice (Earthscan Publishing 2002) 310.

126 Chidi Oguamanam, 'Beyond Theories: Intellectual Property Dynamics in the Global Knowledge Economy’ (2009) 9 Wake Forest Intellectual Property Law Journal 104, 112. 
have protected traditional knowledge through interpretations of contracts in many cases. Contractual agreements are commonly used to enforce 'benefit-sharing agreements' along with non-disclosure agreements which act as trade secrets. These contracts specifically clarify and elucidate the points of the utilization of the knowledge and specifics for benefit sharing. A notable example of this is the agreement between the San and Khoi communities and the Council for Scientific and Industrial Research (CSIR) of South Africa concerning the patents on the traditional use of the Hoodia plant. ${ }^{127}$

The most commonly used contractual agreements are (a) confidentiality or nondisclosure agreements, (b) exclusive license agreements, (c) non-exclusive licensing agreements, and (d) agreements for material transfer. ${ }^{128}$ Among the limitations, there are some major deterrents in this mechanism like high transaction costs, disparity in bargaining powers between contracting parties and lack of legal expertise. So, the question, whether the contract modality is an equitable one or not, still remains unanswered, even though contract could be a very flexible instrument to protect TK.

\section{Way Forward for Bangladesh}

The advent of biotechnology and genetic engineering, protected by IP regime, entails new protection modalities for traditional knowledge. A single model, particularly a 'one size fits all' solution, cannot be applied in isolation to meet the concerning issues of TK. A multiplicity of diverse modalities, including IP and non-IP apparatuses, are essential for the protection and prevention of misuse of TK. Depending on the diverse legal and infrastructural capacities, Bangladesh should attempt to craft a comprehensive model for the protection of TK. The particular protection system should encompass a package of legal, non-legal, and voluntary mechanisms along with adaptations of existing IPRs.

To address this challenge, Bangladesh should initially categorize all kinds of TK within its geographical boundaries and should recognize the efforts and role of the relevant indigenous people from whom TK is derived. Consequently, the country's existing IP rights protection mechanism requires to be efficiently utilized with a focus to maintain an equilibrium between the adequate protection and promotion of the use of TK. However, in the longer term, the development of a sui generis law is needed for responding to the needs of indigenous communities. The government should act pro-actively to adopt a clear national policy to ensure the protection of TK, especially taking India as an example in this regard and the end result must be aimed at

127 Roger Chennells, 'Traditional Knowledge and Benefit Sharing after the Nagoya Protocol: Three Cases from South Africa' (2013) 9 Law Environment \& Development Journal 163, 169.

${ }^{128}$ Charles R McManis, 'Intellectual Property, Genetic Resources and Traditional Knowledge Protection: Thinking Globally, Acting Locally' (2003) 11 Cardozo Journal of International \& Comparative Law 547, 559; see also, Hansen and Van Fleet (n 79) 31. 
formulating an internationally acceptable regime that affords befitting protection to TK holders.

\section{Conclusion}

Given the current legal framework of Bangladesh, a single option or modality cannot comprehensively serve as an appropriate protection mechanism for TK. Since the existing IP regime is immensely inadequate to protect the interests of the TK holders, a sui generis full-fledged model should be established- based on the international instruments- to serve the purpose. This article shows that among the conventional IP instruments, patent can serve as a defensive protection mechanism by utilizing the notion of the prior art, whereas TK holders can collect royalties under the realm of copyright. However, both the instruments offer protection only for a certain period. In this regard, trademarks and trade secrets can be termed as effective tools to protect TK as they provide protection for an indefinite duration. Turning to the geographical indications, it provides for a perpetual protection as long as the traditional quality is maintained. Considering the downsides of classical IP tools, several other possible way-outs have also been suggested like the ABS mechanism, confidentiality agreements and the TKDL models. This article strongly recommends that the national laws concerning intellectual property and genetic resources should be amended to avoid the conflict between the sui generis law and the national legislation. In that way, both existing national laws and the new sui generis law can provide a realistic and appropriate dual framework for protecting the traditional knowledge per se. 